\title{
The Baby Boom and the Stock Market Boom
}

\author{
Kyung-Mook Lim*and David N. Weil ${ }^{\dagger}$
}

March 10, 2003

\begin{abstract}
This paper addresses two issues. The first is whether demographic change was plausibly responsible for the run-up in stock prices over the last decade, and whether the attempt by the baby boom cohort to cash out of its investments in the period 2010-30 might lead to an "asset meltdown." The second issue is whether the rise in dependency that will accompany the retirement of the baby boom cohort calls for an increase in national saving. We analyze these issues using a forward-looking macro-demographic model, and show that they are related via the existence of installation costs for capital. If such costs are sufficiently large, then demographics do have the power to affect stock prices, but "saving for America's old age" is less optimal. However, conventional estimates of capital installation costs are not large enough to explain large stock price movements in response to actual demographic change.
\end{abstract}

\section{Introduction}

The aging of the US population, and the parallel aging of populations in most of the rest of the industrial world, are expected to have far reaching economic, social, and political implications. This paper examines two related issues that arise when one considers the implications of aging for investment.

\footnotetext{
*Money and Finance Team, Korea Development Institute, Seoul, Korea 130-012 Email: limk@kdi.re.kr. The author owes thanks to Chang Min Lee for his research assistance. The views expressed are those of the author and are not necessarily shared by KDI.

${ }^{\dagger}$ Department of Economics, Brown University, Providence, RI 02912 and NBER. Email: David_Weil@brown.edu We thank Douglas Elmendorf and Louise Sheiner for helpful comments.
} 
The first issue that we investigate is the effect of aging on the prices of assets, in particular stocks. The motivation for this line of research is the large discussion, both within the academic community and in popular media, about the role of the baby boom generation in driving the remarkable growth of stock prices over the last decade. To give an example of this sort of analysis, The New York Times wrote (Jan 5, 1998) that "In the 1990's, the performance of the American stock market has been nothing short of amazing.......Most of that performance has come from demographics, as the baby boom reaches the age when it seems wise to invest for retirement...." Believers in the effect of demographics on the stock market also predict that there may be an "asset meltdown" during the period when the Baby Boomers are selling their assets to pay for retirement.

While the link between demographic change and stock prices is a positive question, the second issue that we investigate is normative: whether the United States is "saving enough for its old age." The coming increase in the ratio of dependent elderly to working age adults will, ceteris paribus, lower the average level of consumption. In the face of this coming demographic shock, it may be optimal for the country to save a higher fraction of its income, in order to smooth consumption.

In addressing both of these issues, we make use of a forward-looking macro-demographic model which explicitly models the process of investment. One of the paper's contributions is to show that the two issues that we investigate are much more closely linked than one might initially have thought. Specifically, if it is true that demographics will affect stock prices, the channel must be via an installation cost of capital. And if there is an installation cost of capital, then this will impact the optimal pattern of investment in the face of demographic change.

The rest of this paper is structured as follows. In section 2, we discuss previous literature that has addressed the questions in which we are interested. Section 3 shows basic demographic data for the United States. In section 4 we present and solve the theoretical model that we will be using. Section 5 applies the model to derive optimal paths of consumption and of asset prices in the face of demographic change. The section begins by considering an stylized case of population aging, which is used to develop intuition. It then examines the response of consumption and asset prices to actual forecast demographic change. Section 6 concludes. 


\section{Previous Literature}

A number of studies have approached the question of whether demographic change will affect stock prices by examining cross-sectional profiles of asset holdings or asset purchases as a function of age. For example, Poterba (2001) finds that there is a hump-shaped pattern of asset holdings by age in cross section, but that this pattern is less evident when one looks at cohorts. Given that such a cross-sectional age-asset profile exists, it is straightforward to combine it with data on past and forecast demographic change in order to construct a time series for aggregate asset demand. One can then regress measures of asset prices on the level or change in this projected asset demand series. Poterba examines the relationship between asset demand and the ex-post returns on bills, bonds, and stocks. The results are generally insignificant. As Poterba points out, however, the short time series sample greatly reduces the power of this test. Other researchers who have conducted similar exercises have found more significant demographic effects on stock prices. Brooks (1997), examining data from 14 industrial countries, finds that the presence of a large working-age cohort raises stock and bond prices. Bakshi and Chen (1994) find that the price of stocks in the United States covaries positively with the average age of the adult population. ${ }^{1}$

The approach taken in these studies is largely a-theoretic. More specifically, they implicitly model the demand for assets as being a function of only current demographics. Unless investors are completely myopic, however, the expected rate of return on investments will be a further determinant of how much people want to invest. Thus there will a feedback from the future path of stock prices back to the pattern of investment. And future stock prices will in turn be influenced by future demographics. Dealing with these considerations requires the construction of a general equilibrium model with an explicit formulation of expectations.

In a recent series of papers, Abel $(2000,2001)$ analyzes the effect of a baby boom on the price of capital in the context of an overlapping generations model with forward looking asset prices. His main results are that the arrival of an unusually large birth cohort into its working years will indeed

\footnotetext{
${ }^{1}$ See also Bergantino (1997) and Schieber and Shoven (1997). Both Brooks and Bakshi and Chen stress that an additional effect of population aging is to shift the desired portfolio of asset holders, and thus the relative returns of assets with different risk characteristics. Mankiw and Weil (1989) used a similar approach in analyzing the effect of demographic change on housing prices. Although their demographic variable did a good job of predicting housing prices in sample, its out-of-sample performance has been unimpressive.
} 
lead to a run-up in asset prices; and that there will be a corresponding reduction in prices when an especially large cohort retires. Abel also finds that the effect of demographics on asset prices survives even in a model where the elderly do not run down their assets before death but rather leave intentional bequests. As will be seen below, our results are qualitatively similar to Abel's. However, because the continuous time structure of our model is more amenable to calibration than is his OLG structure, we are able to assess the quantitative impact of a baby boom on asset prices.

The second question that we address in our paper - whether the United States is saving "enough for its old age" - is necessarily difficult to answer using an optimizing economic model. Obviously, if the economy is composed of rational, forward looking agents, and if there are no externalities, then saving decisions will be made in a manner which maximizes the present discounted value of utility, and the answer to the question of whether the country is saving enough will be "yes." However, if the assumptions of the intertemporal maximizing model are violated, it is possible that the country will be saving less than the optimal amount. A natural way in which to assess this possibility is to examine the pattern of saving that would be observed in an optimizing model, and to compare it to the actually observed pattern. If they differ (for example, if the optimizing model predicts that a certain demographic change should result in higher savings, while the actual saving rate remains constant) then this provides evidence that saving may be deficient. Such a finding would provide a justification for government policies to raise the saving rate.

The most notable implementation of this approach to assessing the path of optimal saving in the face of demographic change is Cutler, Poterba, Sheiner, and Summers (1990), hereinafter called CPSS. Surprisingly, CPSS find that forecast demographic change in the US does not call for an increase in the saving rate. The primary reason for this conclusion is that, in addition to incorporating the "dependency" effect, whereby a larger ratio of dependents to workers would lower consumption per capita, CPSS also incorporate into their model two other factors: first, a "Solow" effect, whereby a reduction in the growth rate of the working age population reduces the amount of investment required to hold the capital/labor ratio constant, and second, an accounting for capital deepening, which implies that higher investment lowers the marginal product of capital. In their model, forecast demographic change would indeed lower the level of consumption, but saving in advance of such a demographic shock is not optimal. The results in CPSS are confirmed and extended by Elmendorf and Sheiner (2000). 
One of the key aspects of the model of CPSS (which is discussed further in the next section) is its assumption that the price of capital is constant over time. Put differently, their model excludes exactly the kind of story under which stock prices will be affected by demographic change.

\section{Data}

Demographic changes affects the economy's consumption opportunities both by changing the relative sizes of the working age and dependent populations, and by changing the growth rate of the working age population. One can summarize the former effect by looking at the support ratio, denoted $\alpha$.

$$
\alpha=L F / C O N,
$$

where $L F$ denotes the labor force and $C O N$ the effective number of consumers. A higher value of $\alpha$ corresponds to a better demographic situation, that is, a higher ratio of workers to consumers.

CPSS constructs a measure of consumption "needs" that varies by age, adjusting for the different levels of education spending, medical spending, and other consumption for children, the elderly, and working-age adults. Their summary measure weights people aged under 20 at 0.72 times the consumption need of a working-age adult and people over 65 at 1.27 times the consumption need of a working-age adult. Using these weights, one can construct a need-adjusted support ratio. Figure 1(a) shows the support ratio for the US over the period 1950-2050.

Figure 1(b) shows the other effect of demographics on an economy's consumption possibilities: the growth rate of the working age population. An economy in which the number of workers is growing more quickly will, ceteris paribus, have lower consumption, because of the need to supply new workers with capital.

\section{The Model}

The model on which we base our research is a variation of Abel and Blanchard (1983). We consider an economy made up of altruistically linked dynasties, each of which has a demographic makeup proportional to the economy as a whole. Households make their consumption decisions taking the 
paths of wages, interest rates, and demographics as exogenous. Production and investment are carried out by identical competitive firms which maximize the present discounted values of their cash flows. Firms undertaking investment face installation costs which are a positive function of the ratio of investment to capital. The economy is closed, and interest rates adjust to maintain the equality of saving and investment. All agents have rational expectations, so that in equilibrium the expected paths of all variables will be identical to their actual paths.

Abel and Blanchard show that the equilibrium of the decentralized economy described above will be the same as the solution to a central planner's problem that we describe below - more specifically, the equations of motion and transversality conditions of the two economies are identical. ${ }^{2}$ Further, Abel and Blanchard show that the marginal cost of an additional unit of installed capital faced by a central planner will be the same as the ratio of the market price of installed to uninstalled capital - that is, Tobin's $q$ - in the decentralized economy. The equivalence of the decentralized equilibrium and the central planner's problem allows us to use the dynamics of the latter in studying the effects of various shocks on the economy.

The central planner's problem is the following:

$$
\begin{gathered}
\max \int_{0}^{\infty} u(c) P e^{-\beta t} d t \\
\text { s.t } f(k)=c / \alpha+i\{1+h(i / k)\} \\
\dot{k}=i-(n+\delta) k,
\end{gathered}
$$

\footnotetext{
${ }^{2}$ This equivalence of the decentralized economy with a social planner's outcome is also a feature of the more familiar Ramsey model. It arises, in the most basic sense, because there is an absence of any externality or missing market that would drive a wedge between the two. More specifically, because we consider infinitely-lived dynasties, each of which replicates the country's aggregate demographic status, there is no missing market in which those currently alive and those who will be alive in the future would want to make transactions. Were we to consider an overlapping-generations model, this property would no longer hold.
} 


$$
\begin{array}{ccc}
U^{\prime}(\cdot)>0 & U^{\prime \prime}(\cdot)<0 & U^{\prime}(0)=\infty \\
f^{\prime}(\cdot)>0 & f^{\prime \prime}(\cdot)<0 & f^{\prime}(0)=\infty \\
h(0)=0 & h^{\prime}(\cdot)>0 & 2 h^{\prime}(\cdot)+\frac{i}{k} h^{\prime \prime}(\cdot)>0
\end{array}
$$

$P$ and $\alpha$ denote population and support ratio, respectively. All variables are in per worker terms except $c$, which denotes consumption per capita (that is, total consumption divided by the effective number of consumers, $C O N$, as defined in section 3.). Thus $c / \alpha$ is equal to consumption per worker. Following CPSS, the social planner in our paper maximizes the present discounted value of total, rather than average, utility in the population. ${ }^{3}$

Let $n$ be the growth rate of the labor force and $\delta$ the rate of depreciation. The function $h(\cdot)$ measures installation costs of capital. The property of $h(\cdot)$ makes the total installation cost $i h(i / k)$ nonnegative and convex with a minimum value of zero. Defining $x=i / k$ and $H(x)=$ $1+h(x)+x h^{\prime}(x)$, Abel and Blanchard show that $H(x)$ can be interpreted as Tobin's $q$, the price of capital.

Setting up a current-value Hamiltonian yields

$$
H=e^{-\beta t}\left[P_{t} u\left(\alpha_{t}\left(f\left(k_{t}\right)-i_{t}\left(1+h_{t}\left(i_{t} / k_{t}\right)\right)\right)+y_{t}\left(i_{t}-\left(\delta+n_{t}\right) k_{t}\right)\right]\right.
$$

where $y_{t}$ is the shadow price of a unit of capital at time /it t.

First-order conditions are

$$
\begin{gathered}
P u^{\prime}(c) \alpha\left\{1+h(x)+x h^{\prime}(x)\right\}=y \\
\dot{y}=y(\delta+n+\beta)-P u^{\prime}(c) \alpha\left\{f^{\prime}(k)+x^{2} h^{\prime}(x)\right\} .
\end{gathered}
$$

\footnotetext{
${ }^{3} \mathrm{~A}$ social planner who cared about the average, rather than total, level of utility in the population would act to raise the average consumption of small cohorts relative to that of large cohorts, leading to a path for consumption that would differ from the one we derive here. However, as CPSS point out (see their footnote 17), there is no compelling ethical argument for weighing people in different sized cohorts differently in a social welfare function. A second issue that arises regarding our formulation of utility is that if the social planner is able to control the growth rate of population, then a social planner who cares about the total utility of the population will favor population growth to the point of impoverishment (see Razin and Sadka, 1995, for a discussion of this point). This issue is not relevant to our paper because we take the path of population as exogenous.
} 
Equation (6) states that the present value Hamiltonian is maximized with respect to the control variable, investment. Equation (7) the equation of motion of the shadow price of capital.

Let $N$ denote the size of the labor force. Since $P=N / \alpha$, we can rewrite the first-order conditions as follows.

$$
\begin{gathered}
N u^{\prime}(c)\left\{1+h(x)+x h^{\prime}(x)\right\}=y \\
\dot{y}=y(\delta+n+\beta)-N u^{\prime}(c)\left\{f^{\prime}(k)+x^{2} h^{\prime}(x)\right\}
\end{gathered}
$$

\subsection{Steady state and Dynamics}

Differentiating equation (8) by $t$ gives

$$
\begin{aligned}
\dot{y} & =\dot{N} u^{\prime}(c) H(x)+N u^{\prime \prime}(c) \dot{c} H(x)+N u^{\prime}(c) H^{\prime}(x) \dot{x} \\
& =N\left\{n u^{\prime}(c) H(x)+u^{\prime \prime}(c) \dot{c} H(x)+u^{\prime}(c) H^{\prime}(x) \dot{x}\right\}
\end{aligned}
$$

Rewrite equation (3)

$$
c=\alpha\{f(k)-k x(1+h(x))\}
$$

Differentiating equation (11) with respect to $t$ gives,

$$
\dot{c}=\dot{\alpha}\left\{f(k)-k x(1+h(x)\}+\alpha\left\{f^{\prime}(k) \dot{k}-\dot{k} x(1+h(x))+k \dot{x} H(x)\right\}\right.
$$

Combining equation (4), (9), (10), and (12) gives the following equation which eliminates $y$.

$$
\begin{aligned}
& \dot{x}\left\{H^{\prime}(x)-\frac{u^{\prime \prime}(c)}{u^{\prime}(c)} \alpha k H(x)^{2}\right\}+\dot{k}\left[\frac{u^{\prime \prime}(c)}{u^{\prime}(c)} \alpha H(x)\left\{f^{\prime}(k)-x(1+h(x))\right\}\right] \\
= & H(x)(\delta+\beta)-f^{\prime}(k)-x^{2} h^{\prime}(x)-\frac{u^{\prime \prime}(c)}{u^{\prime}(c)} H(x) \dot{\alpha}\{f(k)-k x(1+h(x))\}
\end{aligned}
$$

Note that equation (12) can be rewritten as

$$
\frac{\dot{c}}{c}=\frac{\dot{\alpha}}{\alpha}+\frac{\left\{f^{\prime}(k)-x(1+h(x))\right\} \dot{k}+k H(x) \dot{x}}{f(k)-k x(1+h(x))}
$$


With a utility function with a constant intertemporal substitution coefficient, $u(c)=\frac{c^{1-\sigma}}{1-\sigma}$, equation (13) becomes

$$
\begin{aligned}
& \dot{x}\left\{H^{\prime}(x)+\sigma \frac{k H(x)^{2}}{c}\right\}-\sigma \dot{k} \frac{H(x)}{c}\left\{f^{\prime}(k)-x(1+h(x))\right\} \\
= & H(x)(\delta+\beta+\sigma \dot{\alpha} / \alpha)-f^{\prime}(k)-x^{2} h^{\prime}(x) .
\end{aligned}
$$

The steady state can be characterized as follows:

$$
\begin{aligned}
x_{s s} & =n+\delta \\
H\left(x_{s s}\right)(\delta+\beta) & =f^{\prime}\left(k_{s s}\right)+x_{s s}^{2} h^{\prime}\left(x_{s s}\right)
\end{aligned}
$$

Equation (4) and (15) characterize the dynamic system. ${ }^{4}$ Figure 2 shows the phase diagram of the model. The steady state is a saddle point equilibrium.

\subsection{Accounting for Leverage}

The analysis so far has been conducted in terms of $q$, which is the value of installed capital. Most discussion of the effects of demographics on stock prices, however, focuses on the changes in the value of the stock market. These changes will be larger than changes in $q$ because firms are not financed $100 \%$ by equity.

Let $e$ be the value of equity per unit of capital and $b$ be the value of debt per unit of capital. These are related to $q$ by the equation

$$
q=e+b
$$

Now suppose that all changes in the value of capital are reflected in equity. We have

$$
\dot{q}=\dot{e}
$$

combining these two equations and doing some re-arranging, we have

\footnotetext{
${ }^{4}$ For a more comprehensive discussion of the model's dynamics, see the appendix of Abel and Blanchard.
} 


$$
\frac{\dot{e}}{e}=\frac{\dot{q}}{q}\left(1+\frac{b}{e}\right)
$$

The ratio $b / e$ is just the ratio of total debt to the market value of equity. The value of this ratio for the US corporate sector in 1995 was .65. Assuming that this degree of leverage is maintained, percentage changes in equity values will be 1.65 times as large as percentage changes in $q$. So a $10 \%$ rise in $q$ would lead to a $16.5 \%$ rise in stock prices.

In the results that we present below, we maintain the convention of presenting data on $q$ rather than on $e$. However, in comparing our results to actual movements in stock prices, we make the adjustment for leverage.

\subsection{Parameterization}

Because the real changes in demographic structure are so complicated, we must rely entirely on the numerical method to analyze the transition dynamics of the economy. We need a explicit functional form of $h(x)$. In empirical studies of q-theory, usually a quadratic adjustment cost function is adopted. ${ }^{5}$ By using a linear functional form for $h(x)$, we can get a quadratic adjustment cost function, which satisfies all assumptions given in this model.

$$
h(x)=\frac{a}{2} x \equiv \frac{a}{2} \frac{i}{k}
$$

There are two key parameters that play an important role in determining paths for both stock prices and consumption in our model. The first is inverse of the intertemporal elasticity of substitution, $\sigma$. The more that the social planner desires to smooth consumption (that is, the lower is inverse of the intertemporal elasticity of substitution), the more investment will respond to future demographic change, and therefore the larger will be the movement in stock prices in response to demographic change. The second key parameter is $a$, which measures the responsiveness of adjustment costs to the investment/capital ratio. The more responsive are adjustment costs, the more stock prices will have to adjust in order to shift investment in response to demographic change. In each case, we have looked to the empirical literature to provide us with a possible range of parameter values. In the case of $\sigma$, we use values of 1 and 10, which bracket most empirical estimates. In

\footnotetext{
${ }^{5}$ See Oliner, Rudebusch, and Sichel (1995), Barro and Sala-i-Martin (1995), and Hubbard (1998).
} 
the case of $a$, we (coincidentally) use the same range of values. Here the sources for our estimates are Hubbard and Kashyap (1992), and Oliner, Rudebusch, and Sichel (1995). As a benchmark, we also consider the case examined by CPSS, where there are no installation costs for capital, that is $a=0$.

To find the transition path between one steady state and another, we convert the differential equations (13) and (15) into the difference equations and employ a grid-search algorithm to find a initial adjustment in the level of $x$ that will lead the economy to the new steady state. We use the parameter values used in CPSS. The depreciation rate is set to 4.1 percent, the U.S. average during 1952-87. The estimated capital's share in gross output is 33.2 percent. The time discount rate, $\beta$ is set to 8.9 percent. $^{6}$

\section{$5 \quad$ Applying the Model}

We begin by applying our model to a stylized version of demographic change, in order to fix intuition. We then turn to an analysis of actual demographic change in the US.

Figure 3 shows the stylized example that we consider: a rapid decline in the support ratio to a new, lower level. Specifically, we consider a drop of $12 \%$ in the support ratio, which is roughly equivalent to the actual drop that will be experienced in the US over the period 2010-2030. For computational simplicity, we model this drop as taking place over a period of three years. As in all problems involving forward-looking asset prices, the issue of when the information about future demographic change became available is central. In this example, we assume that this information was available far in advance.

Figures 4-5 show what happens over time for different values of the installation cost parameter, $a$, and inverse of the intertemporal elasticity of substitution, $\sigma$. Figure 4 shows the path of $q$, the value of capital; figures 5 shows the corresponding paths of consumption.

Several points stand out in these figures. First, the larger are adjustment costs for capital

\footnotetext{
${ }^{6}$ The value of the time discount rate is calibrated so that the steady state marginal product of capital matches the US postwar average. The value used is somewhat higher than standard estimates. The explanation for this gap is that there is no risk in the model, and so the riskless rate of interest is equal to the marginal product of capital less depreciation. In a model that explicitly allowed for risk, the observed marginal product of capital would be consistent with a lower time discount rate.
} 
installation, the larger are movements in the value of $q$. Second, and more subtly, larger adjustment costs lead to consumption being less smooth in the face of demographic change than it would otherwise be. The reason for this phenomenon is that when adjustment costs are high, the strategy of saving in advance of a demographic shock is expensive: at the margin, investments are being made at exactly the time when installation costs are highest. When $a=0$, which is the case considered by CPSS, consumption makes roughly $1 / 3$ of its required steady-state adjustment before the demographic shock actually arrives. In the case where $a=10$, consumption hardly adjusts at all prior to the demographic shock.

Variation in inverse of the intertemporal elasticity of substitution, $\sigma$, has the expected effect in the model. When $\sigma$ is large, consumption tends to be smoother in the face of demographic change. One result of this is that the country starts lowering consumption further in advance of a demographic shock than it would if $\sigma$ were small. A second implication of bigger $\sigma$ is that movements in stock prices are more pronounced than they are when $\sigma$ is small. The reason is that when $\sigma$ is large, the country values consumption smoothing sufficiently that it will engage in it even through it is costly. Thus investment prior to the demographic shock is high, and this must be accompanied by a large value of $q$.

The largest response of stock prices to demographics comes in the case where both adjustment costs and inverse of the intertemporal elasticity of substitution are set at their highest levels. In this case the run-up in $q$, which takes place over roughly 20 years, totals roughly $12 \%$, implying an increase in stock prices of $20 \%$, or roughly $1 \%$ per year. The "asset meltdown" in this case is of roughly comparable magnitude (it is more abrupt than the price run-up, but this is simply a function of the rapid demographic transition in our stylized example.)

Notice that the paths of q depicted in figure 4, combined with the assumption of perfect foresight in the model, imply that investors will hold capital even though they know that they are going to suffer a capital loss. This can occur because we have assumed that capital is the only asset in the economy. Consumers (or a social planner) who want to smooth consumption will be willing to hold capital despite its negative rate of return, in order to smooth consumption. In practice, as we shall see in the next section, actual paths of demographics will lead to a reduction in the expected rate of return to capital, but not to actual negative rates of return. 


\subsection{Actual demographic Change}

We now turn to the analysis of actual demographic paths. This differs from the above example in that not only the support ratio, but also the growth rate of the working age population changes over time. As in the case of the stylized example, we have to choose a date on which the future path of demographics was discovered (we assume that prior this "demographic discovery", expectations were static.) We begin by assuming that demographic discovery took place in 1990; below we explore other possible discovery dates.

Figure 6 show the path of $q$ under different assumptions about the parameters. The most significant finding here is that, even under extreme assumptions, the effect of demographics on stock prices are relatively small. Using values of $a=10$ and $\sigma=10$, the model predicts a run-up in $q$ of $5 \%$ (or an increase in stock prices of $8 \%$ ) over the course of the 1990's. The model predicts that prices will rise slightly further during the first decade of the new century, peaking around 2012. There will then be a decline of roughly $16.5 \%$ in stock prices spread over a period of two decades. Using smaller values of either of the key parameters predicts even smaller movements in stock prices.

Looking at consumption (see figure 7), the model echos the basic message of CPSS. From the perspective of 1990, the optimal response to the "news" of future demographic change was to increase, rather than to decrease consumption. This is the case despite the fact that when the increase in the support ratio arrives, consumption will eventually have to fall.

We now look at the effect of changing the assumed date on which the news of future demographic change arrived. We focus on the parameterization which gives the largest movements in asset prices that is, on the case where $\sigma=10$ and $a=10$. Figure 8 shows the paths of $q$ under different scenarios. $^{7}$ In each case, the path of $q$ is normalized to be equal to 100 in the period before news about demographics arrives. Obviously, the scenarios produce different paths of asset prices immediately after the arrival of news: for example if news about future demographic change arrived in 1970 it would lead to a large fall in the price of stocks, because the working age population was going to be growing very slowly over the next two decades; by contrast, the arrival of news in

\footnotetext{
${ }^{7}$ The data shown in Figure 8 are re-scaled so that the value of $\mathrm{Q}$ in the period prior to discovery are equal to 100. The actual Q values are 1.45 (prior to discovery in 1970), 1.48 (prior to discovery in 1980), and 1.41 (prior to discovery in 1990).
} 
1990 would have little immediate effect on stock prices. But the general message from this picture is that the date of arrival of news makes very little difference for the future path of asset prices. The percentage decline in stock prices over the period 2010-2030 is almost identical in the three scenarios.

\section{Conclusion}

Considering together the issues of optimal response of saving to a demographic change on the one hand, and the effects of demographics on stock prices, on the other, leads to an important insight: if the conditions under which demographic change will have a large effect on the stock market are satisfied, then a country's ability to "save for its old age" is even more sharply limited than had previously been understood. Put differently, if demographics affect stock prices, then the controversial result of Cutler et al. is strengthened.

While the above insight depends only on the theoretical model, our attempts to parameterize the model and to use data on actual demographic change as an input show that the case for a large demographic effect on stock prices is fairly weak. For example, our theoretical model predicts that there will indeed be a decline in asset prices in response to demographic change over the period 2010-2030, but the magnitude of the decline will be far too small to justify the term "meltdown."

\section{References}

[1] Abel, Andrew (2000), "The Effects of a Baby Boom on Stock Prices and Capital Accumulation in the Presence of Social Security" Mimeo, University of Pennsylvania.

[2] Abel, Andrew. (2001) "Will Bequests Attenuate the Predicted Meltdown in Stock Prices When Baby Boomers Retire?" Review of Economics and Statistics 83:4.

[3] Abel, Andrew and Olivier J. Blanchard, (1983), "An Intertemporal Model of Saving and Investment," Econometrica, Vol. 51, No.3, 675-692

[4] Bakshi, G.S. and Chen, Z. (1994), "Baby Boom, Population Aging, and Capital Markets," Journal of Business 67, 165-202. 
[5] Barro, Robert J. and Xavier Sala-i-Martin. (1995), Economic Growth, McGraw-Hill, Inc..

[6] Bergantino, Seteven M., (1997), "Booms, Busts and Babies: The Effect of Demographics on Housing and Stock Prices," MIT mimeo.

[7] Bosworth, Barry and Gary Burtless. (1997), "Social Security Reform in a Global Context," Brookings Papers in Economic Activity.

[8] Brooks, Robin. (1997), "The Effects of Demographic Transition on Stock and Bond Prices", mimeo

[9] Cutler, David M., James M. Porterba, Louise M. Sheiner, and Lawrence H. Summers (1990), “An Aging Society: Opportunity or Challenge?," Brookings Papers on Economic Activity, Vol. 1, 1-56 and 71-73.

[10] Elmendorf, Douglas W. and Louise M. Sheiner, "Should America Save for its Old Age? Fiscal Policy, Population Aging, and National Saving." Journal of Economic Literature 14:3, Summer 2000, p. 57-74.

[11] Hubbard, Glenn H.(1998), "Capital-Market Imperfection and Investment," Journal of Economic Literature, Vol. ,193-225.

[12] Hubbard, Glenn H. and Anil K. Kashyap (1992), "Internal Net Worth and the Investment Process," Journal of Political Economy, Vol. 100, 506-534.

[13] Mankiw, Gregory and David N. Weil (1989), "The Baby Boom , The Baby Bust and the Housing Market," Regional Science and Urban Economics, 19, 235-258.

[14] Oliner, Stephen, Glenn Rudebusch, and Daniel Sichel (1995), "New and Old Models of Business Investment: A Comparison of Forecasting Performance," Journal of Money, Credit, and Banking, Vol. 27, No.3, 806-826.

[15] Porterba, James M.(2001), "Demographic Structure and Asset Returns," Review of Economics and Statistics 83:4.

[16] Razin, Assaf.(1995), and Efraim Sadka. Population Economics. Cambridge, MA: MIT Press. 
[17] Schieber, Sylvester J. and John B. Shoven. (1997), "The Consequences of Population Aging for Private Pension Fund Savings and Asset Prices" in Michael D. Hurd and Naohiro Yashiro, eds., The Economic Effects of Aging in the United States and Japan University of Chicago Press, p. 111-130.

[18] Weil, David N. (1997), "The Economics of Population Aging," Handbook of Population and Family Economics, Vol. 1B, 967-1014. 
Figure 1 (a). Actual and Projected Changes in Support Ratio (Relative to 1990), United States, 1960- 2050

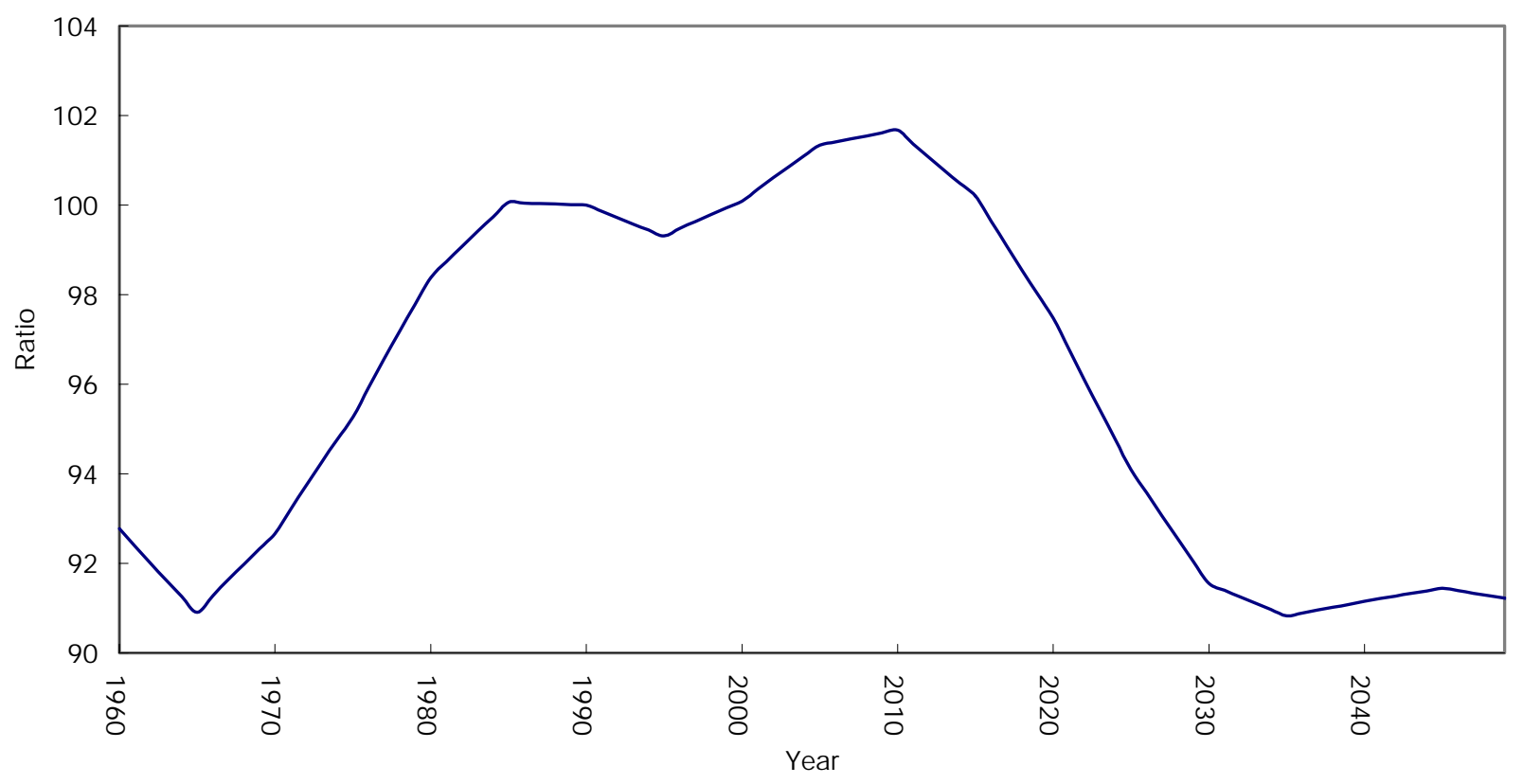

Figure 1 (b). Actual and Projected Changes in Labor Force Growth Rate, 1960- 2050 United States

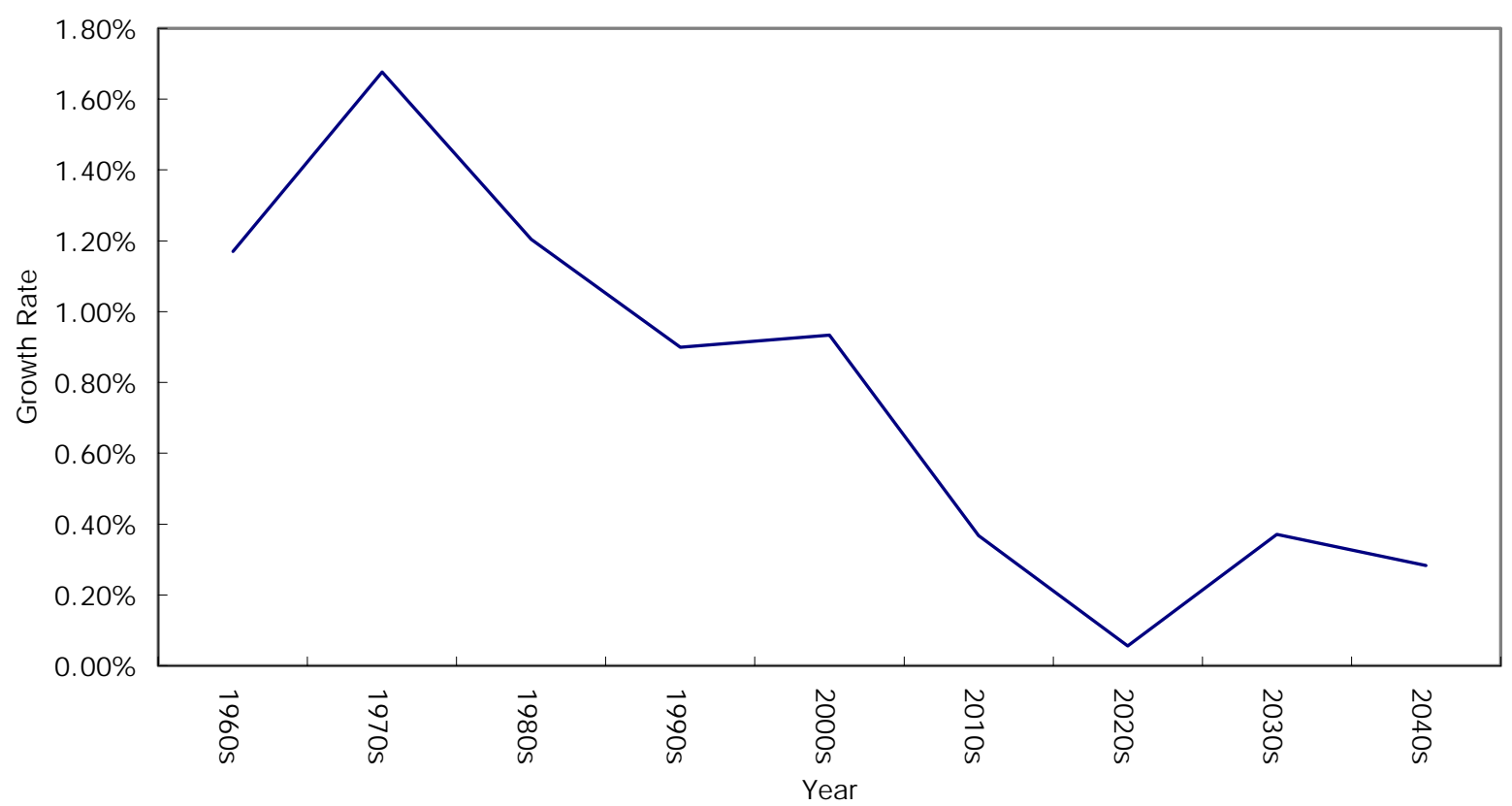




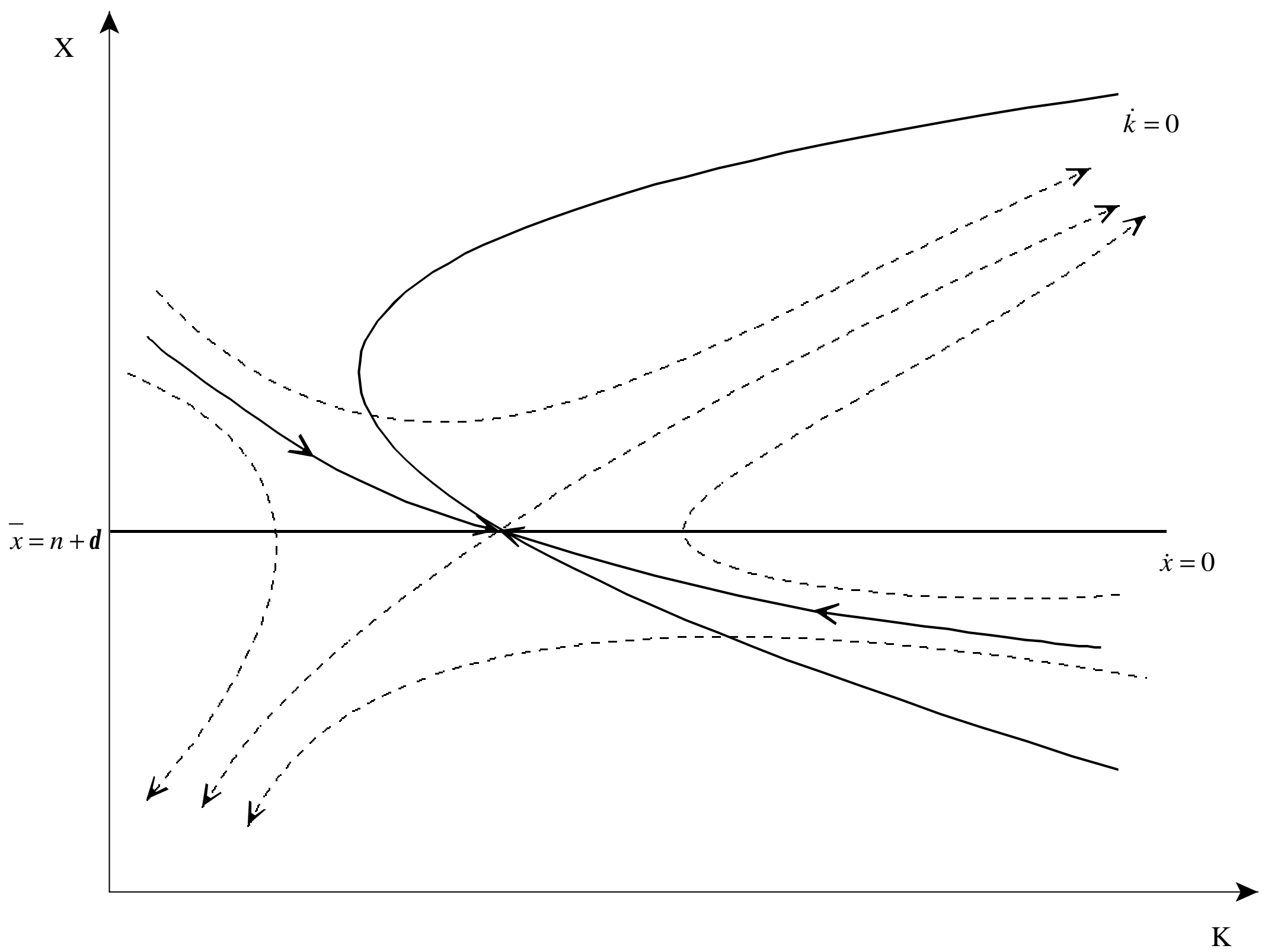

Figure 2 
Demographic Shock in Support Ratio

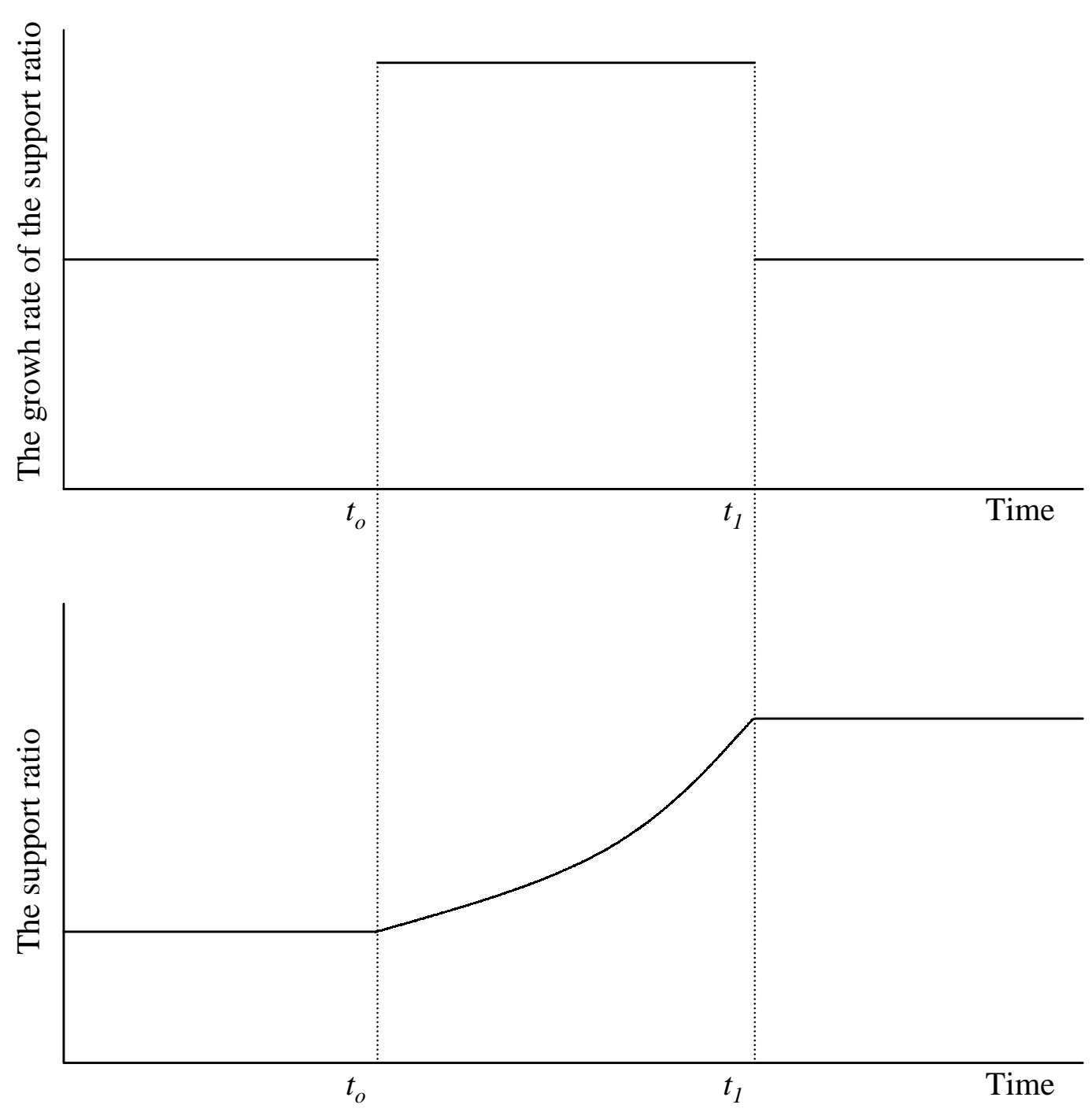

Figure 3 
Figure 4 (a). A Stylized Experiment with Sigma $=1$

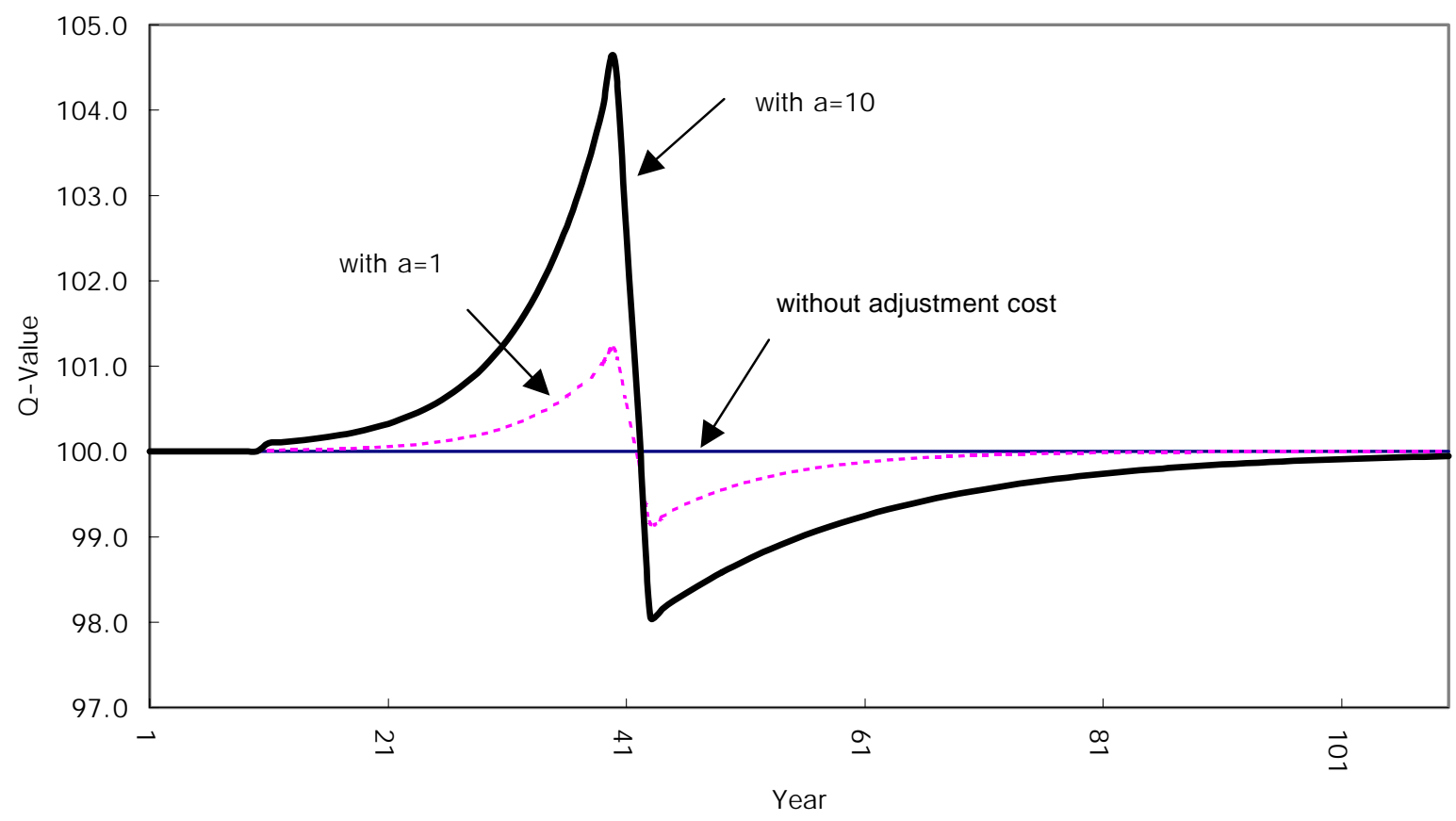

Figure 4 (b). A Stylized Experiment with Sigma $=10$

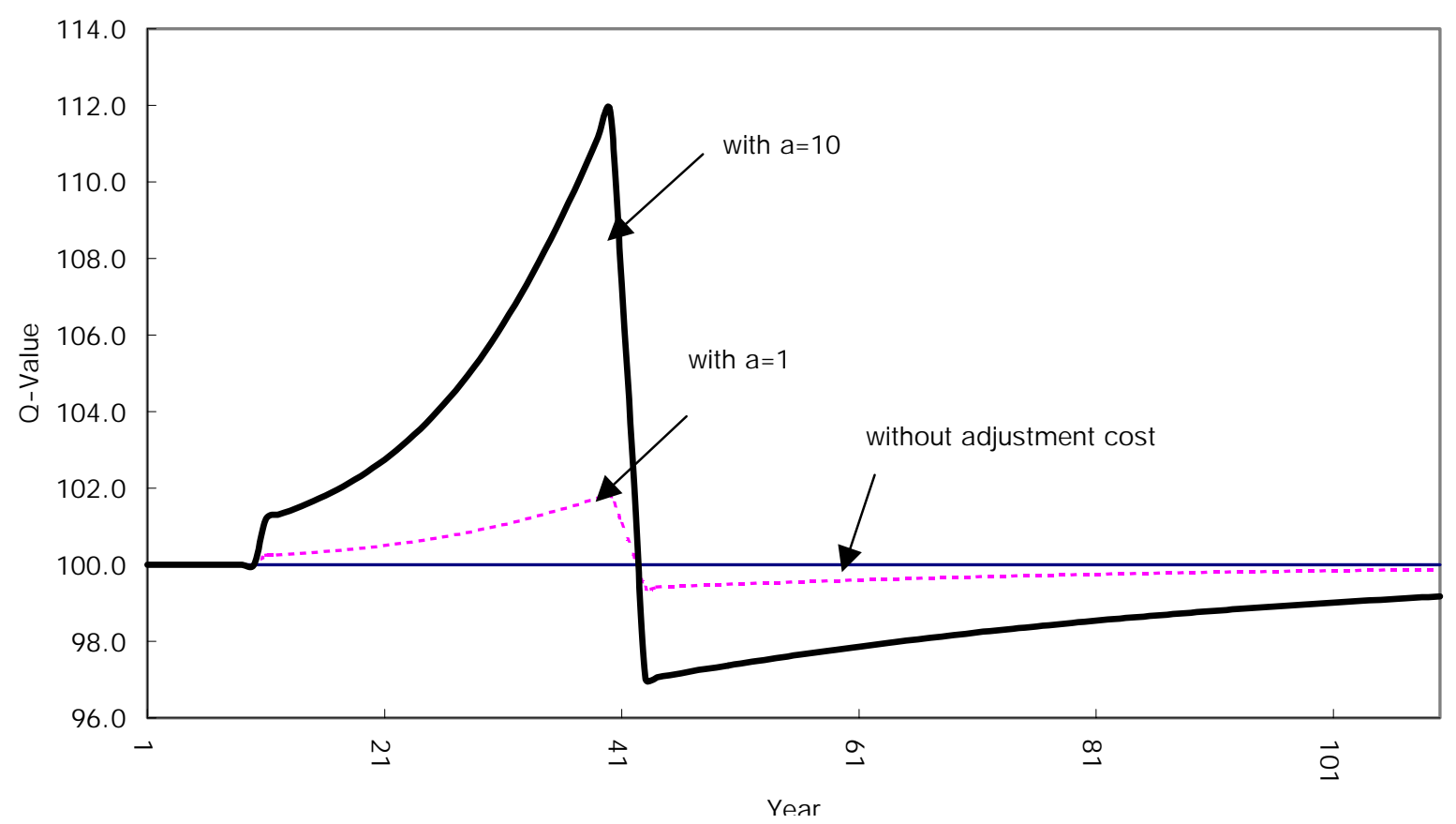

All starting values in the figures are normalized at 100 . 
Figure 5 (a). A Stylized Experiement with Sigma $=1$

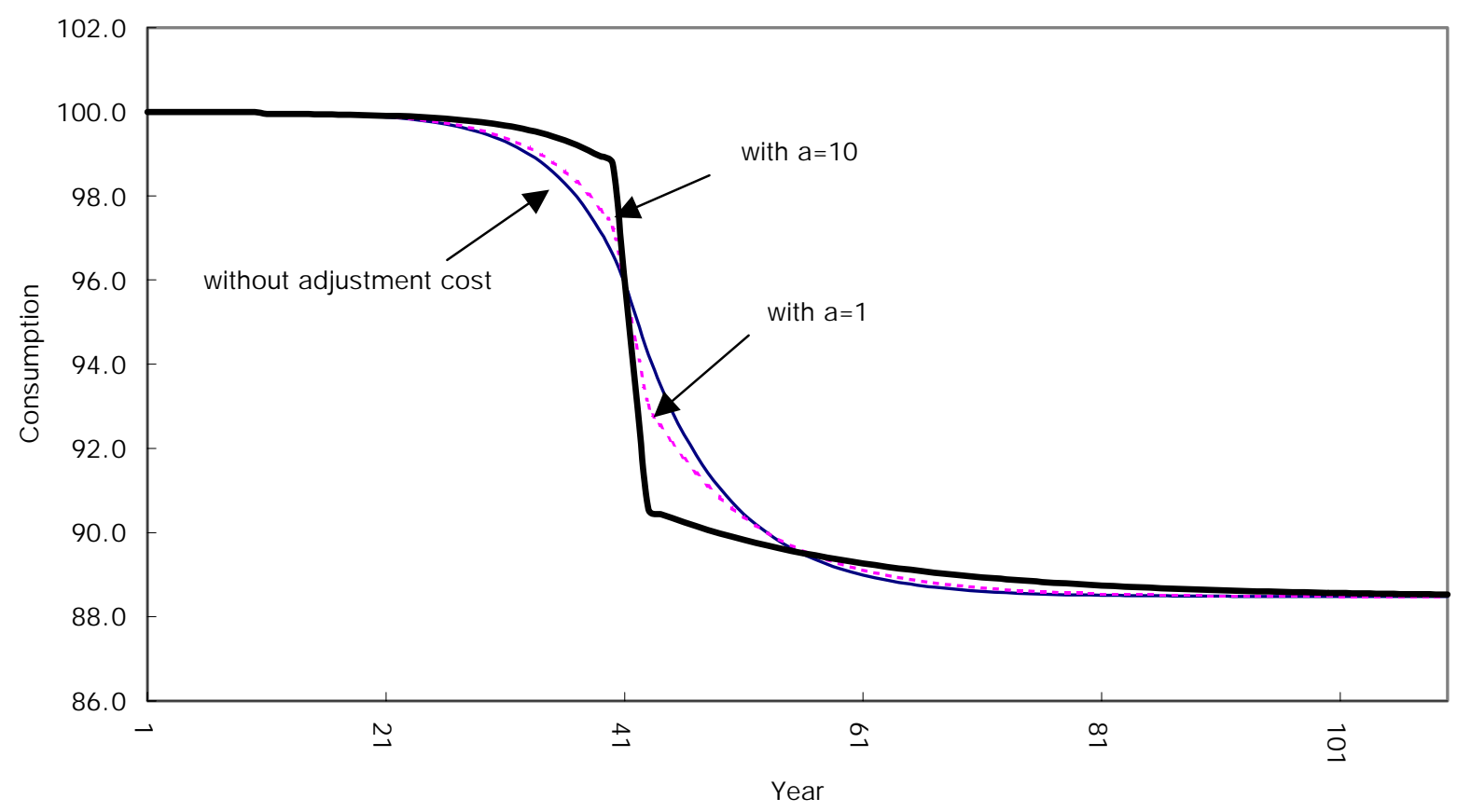

Figure 5 (b). A Stylized Experiment with Sigma=10

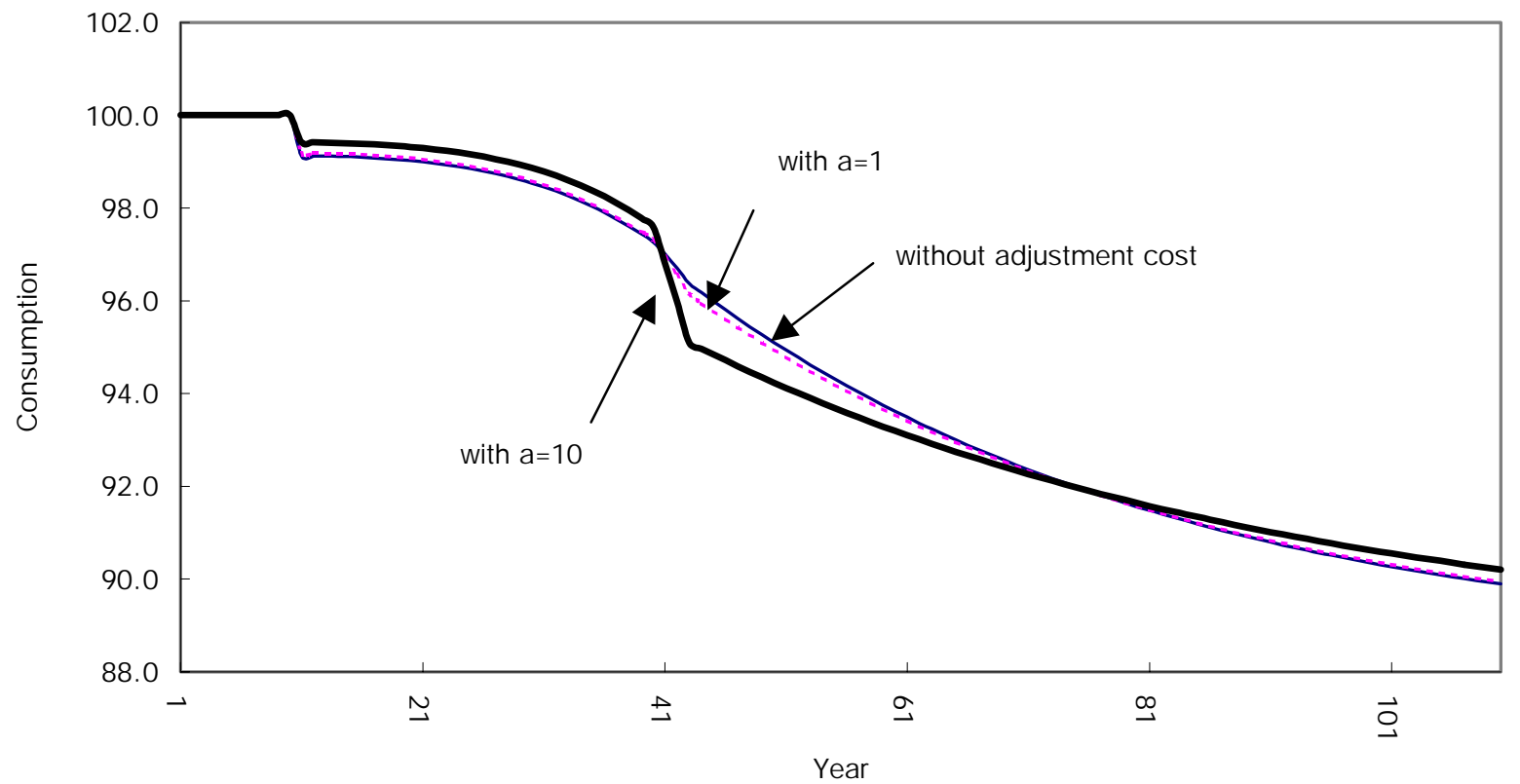

All starting values in the figures are normalized at 100 . 
Figure 6 (a). Actual Demographic Change with Sigma=1

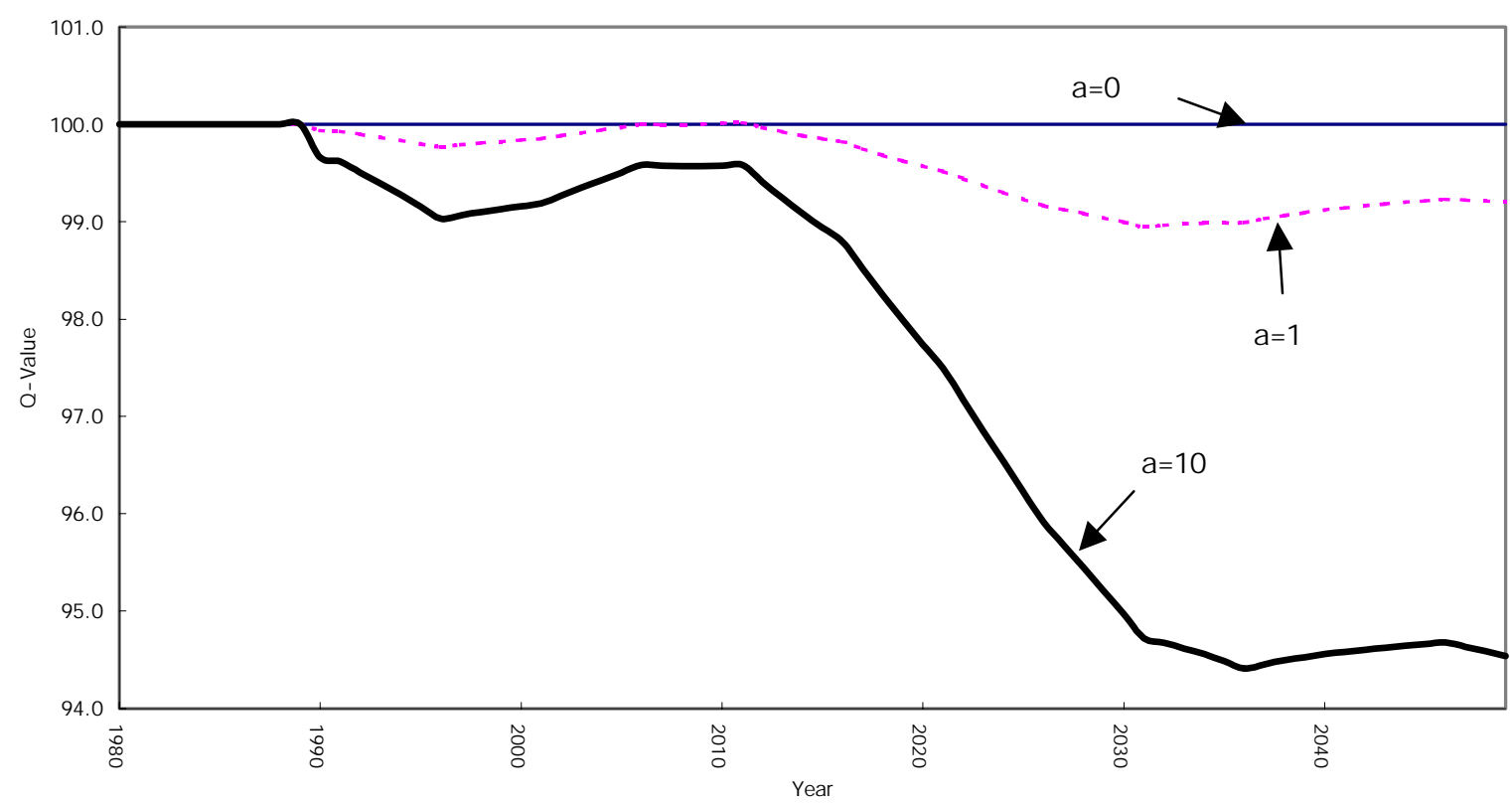

Figure 6 (b). Actual Demographic Change with Sigma $=10$

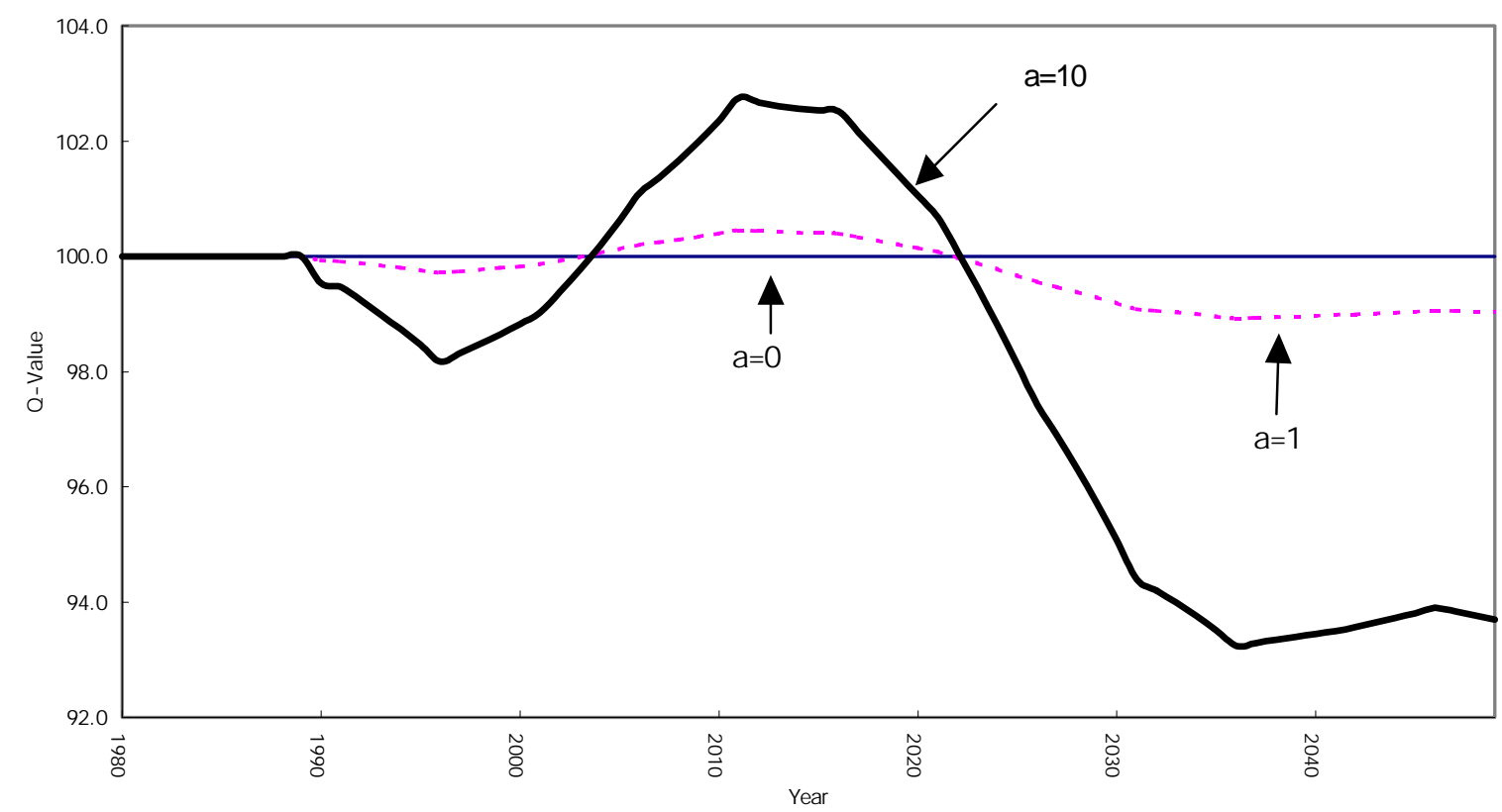

All starting values in the figures are normalized at 100 . 
Figure 7 (a). Actual Demographic Change with Sigma=1

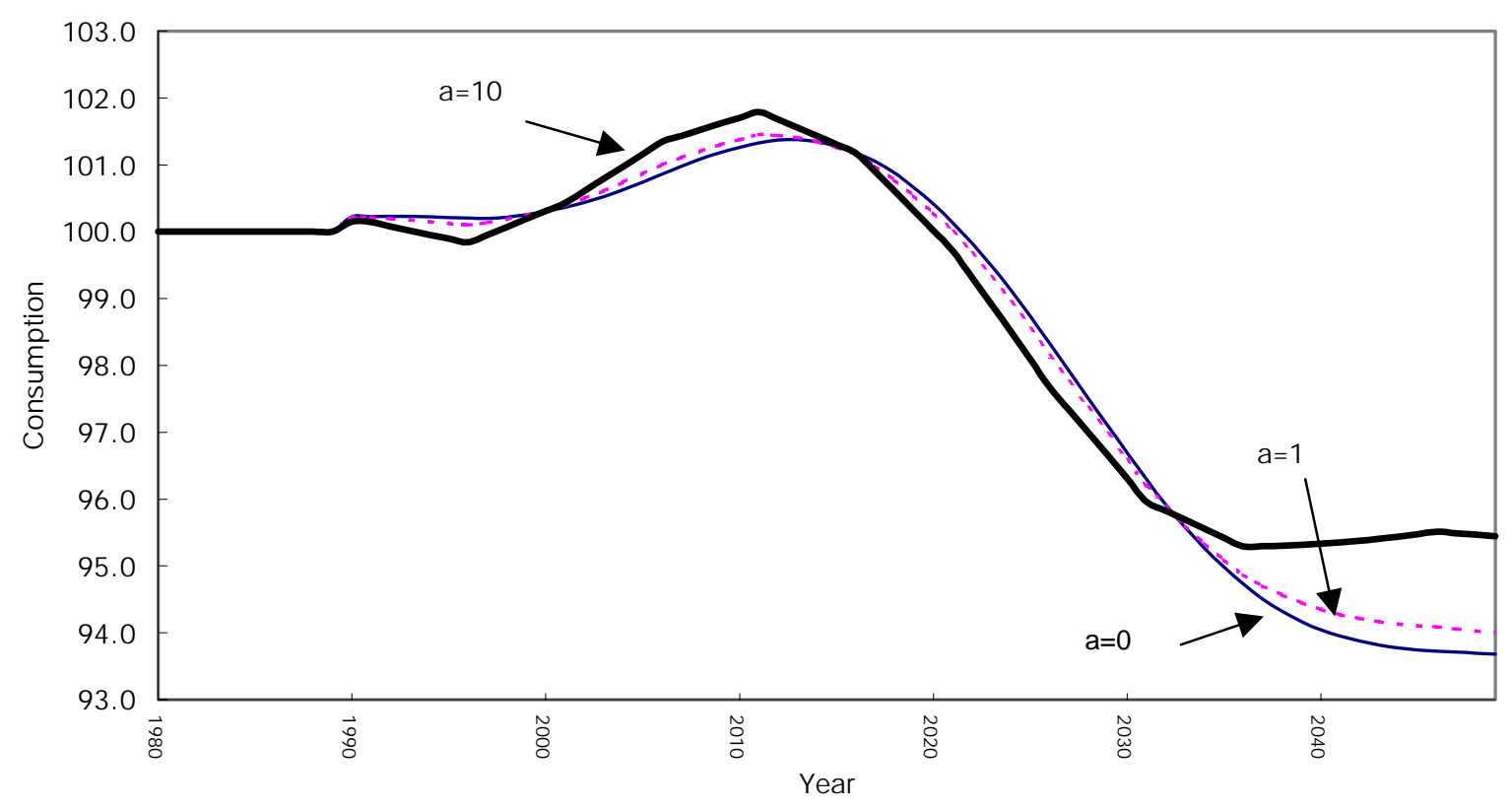

Figure 7 (b). Actual Demographic Change with Sigma $=10$

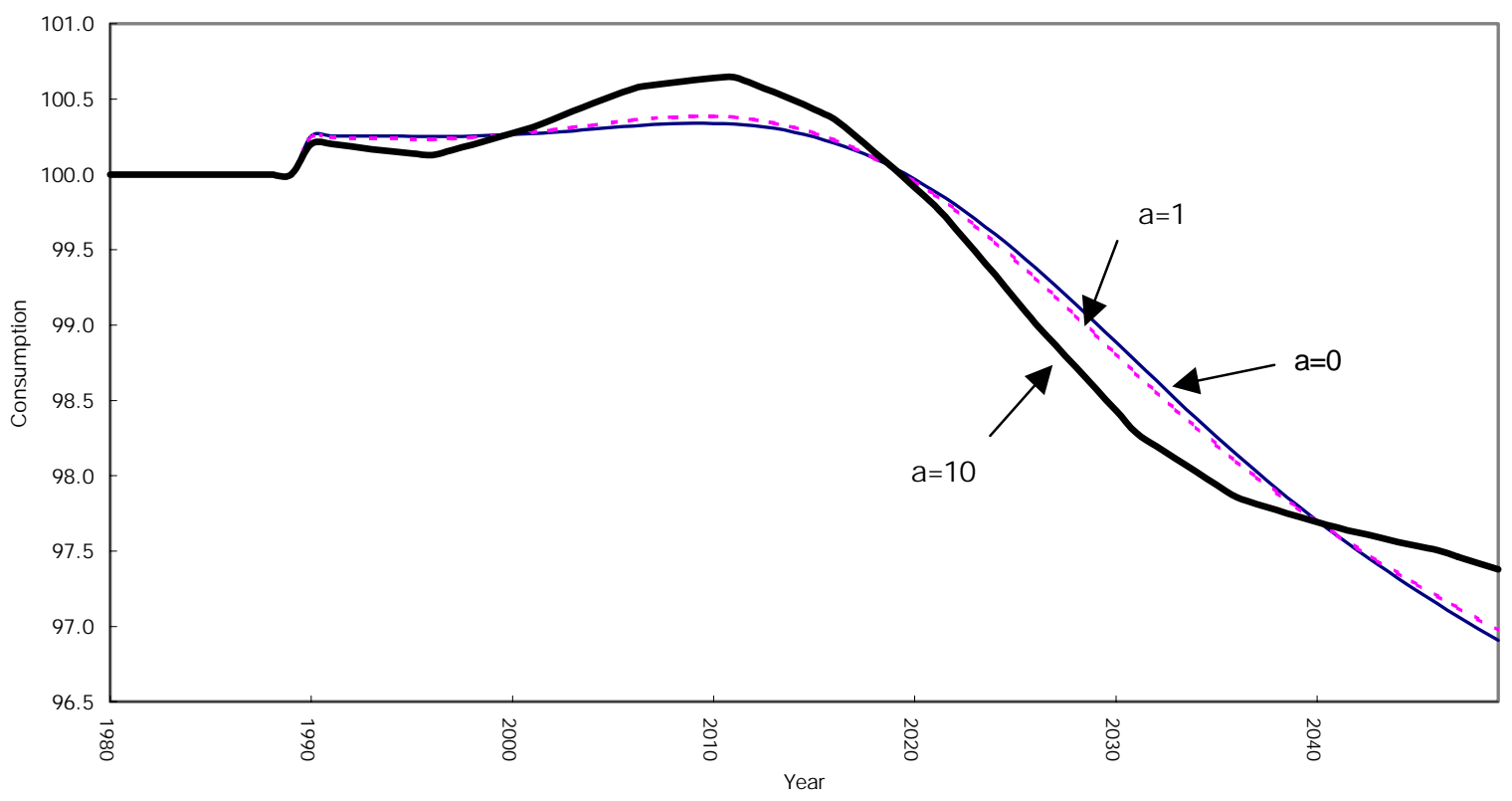

All starting values in the figures are normalized at 100 . 
Figure 8. Sensitivity to Date of Demographic Discovery

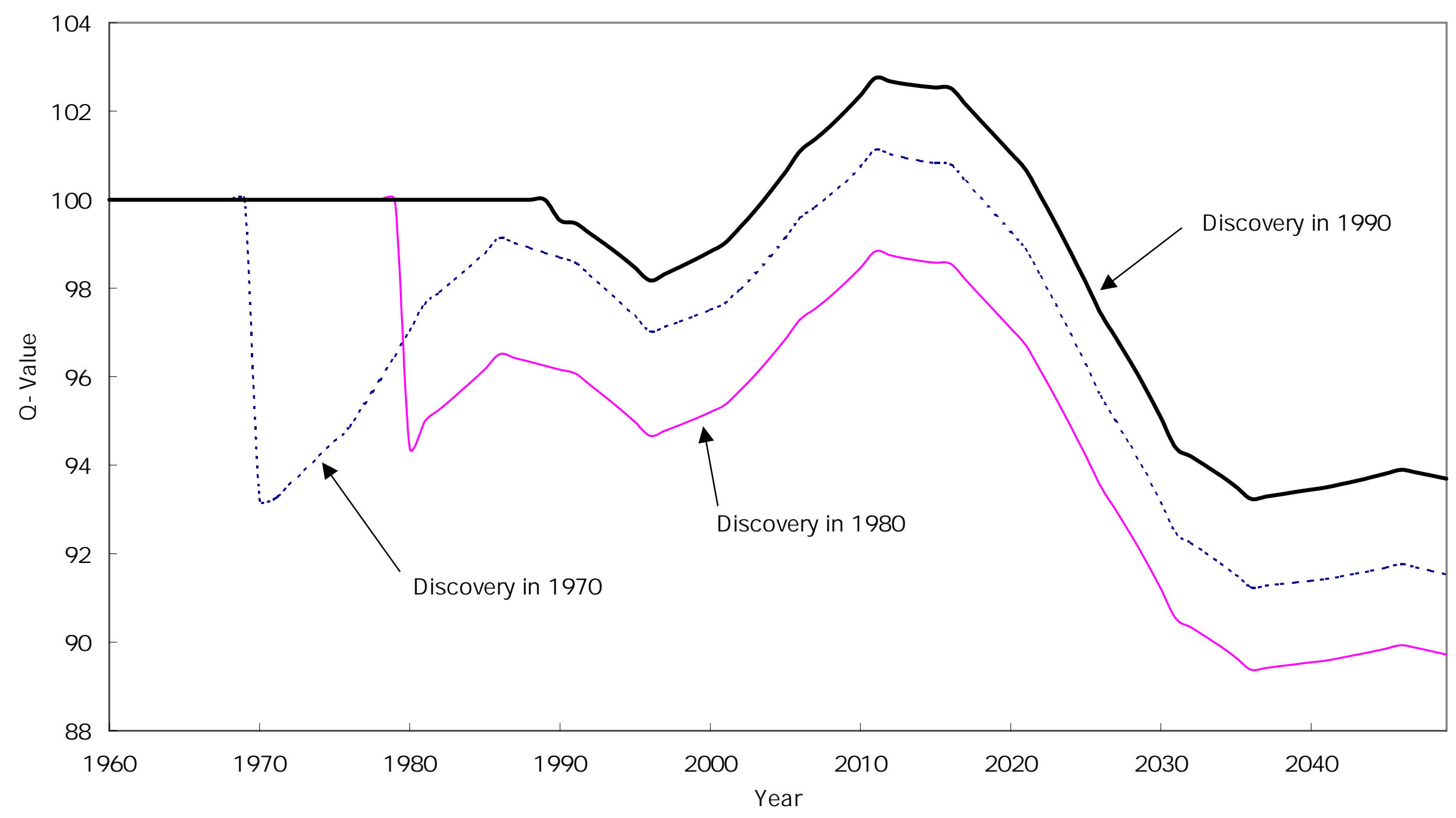

